\title{
Understanding Organizational Evolution: Toward a Research Agenda using Generalized Darwinism
}

\author{
Geoffrey M. Hodgson \\ University of Hertfordshire, UK
}

\begin{abstract}
The terms 'evolution' and 'coevolution' are widely used in organization studies but rarely defined. Often it is unclear whether they refer to single entities or populations. When specific evolutionary processes are suggested, the labelling is often misleading. For example, in the debate over the roles of individual adaptation and competitive selection, the 'selectionist' position of Michael Hannan and John Freeman (1989), which emphasizes the role of selection and stress the limits of individual firm adaptability, is often described as 'Darwinian' whereas opposing views that emphasise adaptability are described as 'Lamarckian'. But these labels are not strictly dichotomous. Scholars have shown that core Darwinian principles, resulting from abstract ontological communality rather than analogy, apply to social evolution. This opens up a research agenda using the principles of generalized Darwinism and the replicatorinteractor framework to help understand the evolution of organizations. Some illustrations of the conceptual value of this approach are provided, including understanding the entwinement of selection and adaptation, the nature and role of organizational routines, the place of strategic choice and the growth of organizational complexity. The framework of generalized Darwinism also helps to bridge apparently divergent perspectives in the business strategy and organizational ecology literatures.
\end{abstract}

\section{Keywords}

Organizations, evolution, adaptation, selection, routines, Darwinism, Lamarckism

\section{Corresponding Author:}

Geoffrey M. Hodgson, Hertfordshire Business School, University of Hertfordshire, Hatfield AL10 9AB, UK.

Email: g.m.hodgson@herts.ac.uk

'Evolution' is a widely-used but ambiguous term. Many organizational researchers (Huygens et al., 2001; Jenkins and Floyd, 2001; Jones, 2001; Lewin and Volberda, 2003; Rodrigues and Child, 2003) refer to 'evolution' or 'co-evolution' while being insufficiently clear what they mean. There is no established, common meaning for these terms. In some academic disciplines 'evolution' evokes Darwinism, but in other quarters (notably in current evolutionary economics) it refers more vaguely and broadly to change. Terms such as 
'evolution' or 'co-evolution' are often used with gravitas, as if they signify something important; but without further specification they actually mean very little. One is left asking what kind of evolutionary theory or meta-theoretical framework is intended.

For example, the editors (Lewin and Koza, 2001) of an issue of Organization Studies devoted to 'co-evolution' - understood broadly as developmental interaction between organizations and their environments - refer to 'the co-evolution framework', 'the coevolution perspective', 'the co-evolution construct', and 'evolutionary theory' (singular), with little further explanation. It is unclear whether 'evolution' refers to a single entity or a population of entities. They do usefully mention the conceptual triplet of 'variation, selection, and retention' but again with no further explanation. What are not told what selection means and what is being retained. (These issues may appear to be simple, but they are not.) The origins of that conceptual triplet are uncited and we are not reminded that this triplet refers to the conceptual core of Darwinism. ${ }^{1}$ As elsewhere (e.g. Nelson and Winter, 1982), there is a remarkable reluctance to mention the $\mathrm{D}$-name. There is also no mention of the fact that Darwin's evolutionary framework is very different from others, such as that of Jean-Baptise de Lamarck or Herbert Spencer. ${ }^{2}$

A prominent debate in organization studies concerns the relative importance of individuallevel adaptation versus population-level selection in explaining overall changes in industry characteristics. The important question is whether selective failure is in fact more important than individual firm adaptation in explaining change in an industry. To a large degree this is a matter of empirical investigation. But empirical enquiry always needs to be guided by clear and carefully-defined concepts.

This article does not bring further empirical evidence to bear. Instead it is argued that the selection-adaptation debate within organization studies over the processes of change has been confused by the use of inexact and misleading terminology, including in regard to the terms Lamarckism and Darwinism. In turn, this confusion has obstructed the use of abstract principles from general evolutionary theory that have been developed since the 1980s in both the philosophy of biology and evolutionary economics (Hull, 1988; Hodgson, 2002; Stoelhorst, 2005, 2008; Stoelhorst and Huizing, 2006; Hodgson and Knudsen, 2006a, 2010b; Aldrich et al., 2008; Pelikan, 2011). These principles are often described as 'generalised Darwinism'.

The aim of this present article is to clear up terminological confusion, instil greater precision, and to indicate how the principles of generalized Darwinism can be useful as an overall framework for helping to understand organizational evolution. In fact, Darwinism is the only complete over-arching theoretical framework available for understanding worlds with populations of entities that are struggling for locally and immediately scarce resources. No viable alternative general conceptual framework for addressing evolution in complex population systems exists. Non-Darwinian approaches leave key elements explained, such as theories of cultural evolution that fail to address the origins of culture or of human agency. If generalized Darwinism is rejected, then what is intended by 'evolution' or 'coevolution' must be clearly specified. Generalized Darwinian principles also add to the research agenda by framing the issues involved in explaining empirical outcomes. Persistent misuse and imprecision of terminology have obstructed the introduction of theoretical insights from generalized Darwinism,

The first section establishes that Darwinism and Lamarckism are not mutually exclusive. The second section shows that for the Lamarckian description to be meaningful independently of the question of its validity - a distinction between genotypes (more 
generally, replicators) and phenotypes (more generally, interactors) is required. This distinction is of much broader significance and transcends the old debate surrounding Lamarckism. The third section argues that social evolution is Darwinian in substance (Veblen, 1899; Campbell, 1965; Hodgson and Knudsen, 2010b) and clarifies the nature of this claim. Contrary to widespread belief, Darwinism embraces rather than excludes such phenomena as intentionality, learning and adaptation. The fourth section shows that organizational adaptation or development cannot be ignored, especially in a fully-fledged Darwinian theory. Contrary to a widespread supposition, Darwinism emphasizes both development and selection. The fifth section explores shows how the replicator concept from generalized Darwinism helps understand the evolution of complexity. The sixth section illustrates some of the implications of this framework for understanding the evolution of routines. The seventh section concludes the essay and points to further implications of the conceptual framework.

\section{The Confusion over Darwinism and Lamarckism}

For various reasons, social scientists have had a very uneasy relationship with Darwinism (Degler, 1991). Worries about 'social Darwinism', misleading portrayals of Darwinian selection as 'blind', and false claims that Darwinism downplays or excludes intentionality, have all helped to dissuade social scientists from addressing Darwinian principles. In fact, Darwin fully acknowledged the role of intentionality: he simply required that intentions should be explained in causal terms. He never described evolution as blind. He did not treat the selection environment as always given (sexual selection being an important example of a changing environment, depending on adaptations in the other sex), and gave important examples of environmental interaction and niche-construction. While Darwinism has been abused in the past, many contemporary worries turn out to be ungrounded. ${ }^{3}$

Partly because of fears about Darwinism, and partly because of a belief in the appropriateness of the other label, many prominent social scientists, have described social or economic evolution as 'Lamarckian., ${ }^{4}$ In many cases the 'Darwinian' label is even ignored or dismissed.

The dispute within organization science over the relative importance of adaptation and selection (Baum, 1996; Lewin and Volberda, 2003), and the extent to which firm routines can change in individual firms, is sometimes described as a contest between 'Darwinian' and 'Lamarckian' conceptions of organizational change (Usher and Evans, 1996). The seminal work of Michael Hannan and John Freeman (1989) is described by many as 'Darwinian' because it stresses selection in a relatively static industry-level environment, and gives a low estimate for the possibilities of individual organizational adaptation (although in later work there is a stronger recognition of adaptation and organization-environment interaction). ${ }^{5}$

Van de Ven and Poole (1995) mistakenly confine the Darwinian evolution of organizations to cases where traits are inherited through inter-generational processes, whereas Lamarckian evolution means that traits can be acquired within the lifetime of an organization through learning and imitation. Many endorse this distinction and some promote Lamarckian evolution over Darwinian ideas, without much detailed consideration of the detailed mechanisms.

John Wilkins (2001) shows that 'Lamarckism' as an ambiguous term with three prominent and different meanings: that acquired characters can be inherited, that evolution leads to greater complexity, and that adaptation is guided by volition. ${ }^{6}$ The second and third meanings say nothing about inheritance, which is the key element in the first meaning. 
The volitional acquisition of characteristics is often contrasted to the allegedly 'blind' or random mutations in some versions of Darwinism. But Darwin fully recognized intentionality and never wrote of random mutations. Core Darwinian principles are inclusive enough to accommodate contrasting accounts. They are also consistent with the fact that intentionality and other capacities such as conscious prefiguration are much more highly developed among humans.

There is a general consensus that Darwinism involves three core principles of inheritance, variation and selection. This can be confirmed by reading the long, final paragraph of Darwin's Origin of Species (1859), where the three concepts are clear. Darwin also emphasized the complex development of individual organisms in response to environmental conditions, and how sometimes the behaviour of organisms can lead to environmental changes. For him, selection neither excluded nor downplayed adaptation.

Darwin himself believed that the inheritance of acquired characters was possible. In that sense he was a Lamarckian! Later many biologists turned against the idea of Lamarckian inheritance. ${ }^{7}$ But logically, and in principle, Darwinism and Lamarckism are not mutually exclusive, contrary to many suggestions in the literature.

Some acquired characters, such as ageing and injuries, are not beneficial. But for species to evolve the effects of deleterious acquired characters must be restricted. Accordingly, Lamarckism depends on the Darwinian principle of selection in order to explain why any propensity to inherit acquired impairments does not prevail. As Richard Dawkins (1986, p. 300) argues, 'the Lamarckian theory can explain adaptive improvement in evolution only by, as it were, riding on the back of the Darwinian theory.' Lamarckism, if valid in any particular domain, depends on Darwinian mechanisms of selection for evolutionary guidance. If Lamarckism is valid then it must be complemented by Darwinian selection.

\section{Establishing the Replicator-Interactor Distinction}

Lamarckism involves the inheritance of acquired characteristics. This section shows how a more detailed examination of the notion of inheritance - including the Lamarckian possibility - depends on the replicator-interactor distinction. Inheritance means more than merely 'passed on.' A dog catches fleas and passes some of them to another dog. Is that Lamarckian inheritance? If so, the fleas must be regarded as an acquired character and their jumping from one animal to another must be treated as inheritance.

As David Hull (1982) points out, to make the Lamarckian claim meaningful, inheritance must be distinguished from infection or contagion. The genotype-phenotype distinction or a relevant equivalent serves this purpose. It is only with such a distinction that inheritance can be properly defined and distinguished from catching colds or fleas.

The genotype-phenotype distinction was introduced in biology in the twentieth century. ${ }^{8}$ An infection or contagion affects the phenotype, not the genotype. By contrast, the Lamarckian inheritance of acquired characters would mean that a development in a phenotype can affect its own genotype, by some presumed internal process. The difference between Lamarckian inheritance and contagion becomes clear through the concepts of genotype and phenotype. But their significance extends far beyond that.

The genotype is a mechanism for storing and passing on information. It guides the development and behaviour of the phenotype, in interaction with its environment. The phenotype is an entity that hosts the genotype. The term replicator is a generalisation of 
genotype, and the interactor is a generalisation of phenotype (Hull, 1988; Brandon, 1996). These concepts are important when we address social entities hosting information-retaining and developmental mechanisms. ${ }^{9}$

Following Hull (1988), Hodgson and Knudsen (2010b) define an interactor as a relatively cohesive entity that hosts replicators and interacts with its environment in such a way as to lead to changes in the population of interactors and their replicators. Social organizations are obvious candidate interactors.

Hodgson and Knudsen (2010b) regard a replicator as consisting of program-like bits of information held by an interactor, which can represent adaptive solutions to problems and guide its development. ${ }^{10}$ A genome is a biological replicator. But there are other replicators, such as routines in organizations (Nelson and Winter, 1982), which also hold information and guide behaviour. Replication refers to the passing of such problem-solving or developmental information from one entity to another. Replication and inheritance are treated as synonyms.

The replicator-interactor distinction is a conceptual advance that helps develop the evolutionary research programs in organization studies and other social sciences. Once the key role of routines to retain potentially replicable instructions is appreciated, we can focus on how these instructions trigger developmental processes and thereby become expressed in particular entities. This helps social scientists study the learning processes that are situated within a broader selection environment.

With their 'routines as genes' metaphor, Nelson and Winter (1982) suggested the possibility of a social replicator. ${ }^{11}$ But the idea of social replicators has meet resistance from biological reductionists and those that deny that social evolution is essentially Darwinian. I must be emphasized that replicators are not cohesive entities in themselves: they are informational mechanisms hosted by interactors (which are cohesive entities). It also must be stressed that the mechanisms of replication are very different in the biological and the social spheres. But some crucial, problem-solving information is copied and transmitted from organization to organization, and this amounts to social replication.

As established above, in order to consider the possibility of Lamarckian inheritance in social evolution we must first identify the replicators and interactors in the social domain. Lamarckian social evolution would require social replicators (not biological replicators such as genes) that were affected by the acquired character of its interactor. If ideas are treated as replicators then their passing from person to person would not be the inheritance of acquired characters because the ideas themselves have been defined as replicators and not characteristics. The spreading of ideas from one interactor to another is an example of contagion, not Lamarckism.

Inspired by Darwinism, American pragmatist philosophers such as Charles Sanders Peirce (1878), William James (1890) and John Dewey (1922) reached a solution to the philosophical problem of reconciling ideas with materially-grounded evolutionary processes. They regarded psychological habits as the foundations and preconditions of ideas. For pragmatists, habits are acquired dispositions that fuel beliefs. Pragmatist psychology and philosophy are undergoing a revival (Joas, 1993), and they are supported by experimental and neurological evidence indicating that our underlying habitual dispositions are at work well before make conscious decisions (Hodgson, 2010). The American institutional economist Thorstein Veblen (Camic and Hodgson, 2011) was strongly influenced by pragmatism and he argued accordingly that habitual and instinctive dispositions were at the foundation of social institutions. ${ }^{12}$ 
Habits are the most elementary replicators in social evolution. They are learned dispositions to behave in a particular way in particular circumstances. They are hosted by individuals (their immediate interactors). Consider the replication (copying) of habits. Learning a new language, we imitate and repeat. We are corrected. This goes on until our responses are ingrained in habit. Gradually the knowledge of the language is transferred from one person to another. The replicators are replicated. The process of habit replication relies on behavioural imitation. ${ }^{13}$ In all cases of habit replication, and unlike genes in biology, there is no direct copying from replicator to replicator. ${ }^{14}$

Further examples of social replicators include routines, which refer to capabilities of organizational teams to carry out sequences of actions. Routines are hosted by organizations as their interactors, and in turn are built on the habits of the individuals involved. There is further discussion of routines in sections five and six below.

Both habits and routines involve some automaticity, but neither is mindless. They are essential for individuals and organizations to deal with complex and changing information.

\section{The Nature and Status of Generalized Darwinism}

The claim that socio-organizational evolution is Darwinian rests on social ontology. Hodgson and Knudsen (2006a, 2010b) use the term 'complex population system' to refer to sets of individually different and demarcated entities that interact with the environment and each other. By definition they face immediately scarce resources and struggle to survive, whether through conflict or cooperation. They adapt and may pass on information to others, through replication or imitation. Examples of complex population systems are plentiful both in nature and in human society. They include every biological species, from amoeba to humans. And importantly for social scientists, they include human organizations, as long as organizations are cohesive entities having some capacity for the retention of information. An economic example is an industry involving cohesive organizational entities such as business firms.

In this manner, the common ontological features of all complex population systems are established, including in nature and human society, without ignoring the huge differences of detail between them.

Crucially, the evolution of any complex population system must involve the three Darwinian principles of variation, selection and retention (Campbell, 1965). These abstract principles do not themselves provide all the necessary details, but nevertheless they must be honoured, for otherwise the explanation of evolution will be inadequate. In particular, investigations into complex population systems must address (a) the sources and replenishment of variety in the population, (b) how information is passed from one entity in the population to another, and (c) why some entities are more successful in surviving or passing on information than others. These three explanatory requirements map onto the three core Darwinian principles of variation, replication and selection. To make this conceptual move, these Darwinian principles have to be defined in sufficiently abstract and general terms, so that they are no longer confined to the biological domain (Hull, 1988; Hodgson and Knudsen, 2010b).

Contrary to much of the organization studies literature, Darwinism does not have a narrow meaning - such as focusing on selection to the neglect of other processes, or referring to specific kinds of inheritance mechanism found in biology. Darwinism is the only known overarching evolutionary framework that tackles the ontological phenomena of variation, selection 
and retention in complex population systems. Existing rival approaches in this context turn out to be less-encompassing or wrong. ${ }^{15}$

The misleading claim by some social scientists that social evolution is Lamarckian is a distraction from the compelling conclusion that it is Darwinian in general and inclusive terms, and that generalized Darwinian ideas can be helpful in understanding the processes. By contrast, Lamarckism provides an inadequate evolutionary framework, notwithstanding processes in social evolution that seem superficially to be Lamarckian.

The idea that social evolution is Darwinian does not mean that social evolution is determined solely by biological phenomena. By contrast, social evolutionary entities and processes are identified. Vague terms such as 'evolution' can be given a much clearer meaning.

Contrary to some accounts, the idea of generalizing Darwinism has less to do with biological metaphors or analogies (although metaphors are unavoidable in science). Instead of analogies, which are typically inexact and sometimes treacherous, generalized Darwinism relies on the claim of common abstract features in both the social and the biological world; it is essentially a contention of a degree of ontological communality, at a high level of abstraction and not at the level of detail. This communality is captured by concepts such as replication and selection, which are defined as precisely and meaningfully as possible, but in a general and abstract sense.

Ontological communality implies neither detailed similarity nor analogy. The fact that Newton's laws of motion apply to billiard balls, spacecraft and planets does not mean that these entities are similar. And no analogy is invoked in the mathematical application of these laws.

As the evolutionary economist J. Stanley Metcalfe (1998, p. 36) pointed out, abstract evolutionary principles in complex population systems might have been developed first outside of biology: 'Evolutionary theory is a manner of reasoning in its own right quite independently of the use made of it by biologists. They simply got there first'. But it is legitimate to describe these general evolutionary principles as Darwinian, because (apart from developing the replicator-interactor distinction) Darwin did get there first, and he also rightly hinted that his general principles might apply to social evolution (Hodgson and Knudsen, 2010b, pp. 5-6).

Observers of 'evolution' or 'coevolution' in organization studies are obliged to say more clearly what they mean. If they avoid the Darwinian label, then further explanation is required. Indeed, in complex population systems, the core Darwinian principles of variation, selection and inheritance offer the only over-arching conceptual framework yet available.

The identification of distinct social replicators and interactors is a key step in elaborating the proposition that abstract Darwinian principles apply to evolution in both nature and society. The remaining but hugely important task is to demonstrate their significance.

\section{Evo-Devo: Embracing both Selection and Adaptation}

Although the mechanisms and details are very different, aspects of the famous 'evo-devo' dispute in biology concerning the relative roles of development, selection and genotypic transmission (Wimsatt, 1999; Stadler et al., 2001; Baguñà and Garcia-Fernàndez, 2003) are relevant for the debate concerning the relative roles of selection and adaptation in organizational studies. The evo-devo debate establishes that selection, development and 
adaptation are generally inter-twined and inseparable processes. Darwin himself did not put a one-sided or exclusive emphasis on selection - he fully considered the development of organisms - and Darwinian theory must logically embrace development and adaptation as well as selection.

Replication, development, adaptation and selection are all essential features of evolution in population systems (Hodgson and Knudsen, 2010b). Consideration of their relative effects is an empirical as well as a theoretical matter, but the empirical outcome would not make any of these features inessential. In any real population system, both selection and adaptation are bound to occur. As established below, selection generally requires adaptation in complex population systems.

Selection occurs because organizations differ both in their inherent characteristics (Nelson, 1991) and their local environments. Some firms go bankrupt. Some are so successful that their routines are copied by other firms. Others lead to successful spin-offs (Dahlstrand, 1998; Klepper, 2008; Bünstorf, 2009). In principle, such differential success and replication amounts to selection, according to its technical definition (Price, 1995; Hodgson and Knudsen, 2010b). Selection is a major reason for changes in the overall profile of a population of organizations. ${ }^{16}$

Turning to adaptation, this term is used in different ways and requires clarification. In the organizational studies literature it typical refers to a change in a specific organization rather than an environmental or other change. For Daniel Levinthal (1992, p. 432) 'adaptation is defined to have occurred when an organization changes its strategy, structure or some other core attribute to fit some new environmental contingency.' More narrowly, for Ross Brennan and Peter Turnbull (1999, p. 182): 'Adaptations can be defined as behavioural modifications made by one company, at the individual, group or corporate level, to meet the specific needs of another organization.' Although this focuses appropriately on organizational change, it overly restricts adaptations to serving the undefined 'needs' of another entity.

The concept of adaptation has acquired different meanings in biology and organization studies. In biology, adaptation refers to change in a whole population, including population changes resulting from natural selection. In organization studies and business economics it often is applied to changes in any one organization.

It is not easy to clear up this terminological mess, but I suggest the following solution. When addressing organizations and their strategic dilemmas, the primary matter is the capacity of an organization to change, in a manner that improves its performance by some appropriate criterion, and increases its chances of survival.

Organizations are more than the sums of their individual members. They involve structured interactions between individuals. The capacity of any organization to change - even a small firm - depends partly on structured internal relations and does not depend on the intentions or attributes of individuals alone. Organizational adaptability is much about internal structures and procedures and their capacity to enable appropriate change. The internal culture of the firm is intimately connected to those structures and procedures, as well as to the values and beliefs of individuals (Schein, 1996; Sørensen, 2002).

We may define organizational adaptability as the capacity of an organization to change its strategies, structures, procedures or other core attributes, in anticipation or response to a change in its environment, including changes in relations with other organizations. The resulting adaptations do not necessarily improve performance by some criterion, but they are generally intended to do so. 
Here we may forge a link with the growing literature on routines (Nelson and Winter, 1982; Cohen and Bacdayan, 1994; Cohen et al., 1996; Becker, 2008). Routines may be defined as organizational dispositions to energise conditional patterns of behaviour within teams, involving repeated sequential responses to cues that are partly dependent on social positions in the organization (Hodgson, 2008). Establishing a routine in a firm means building or using internal relations and positions that enable repeated sequential behaviours. These in turn help to develop particular habits and other specific conditional dispositions among individuals. Routines, as noted above, are organizational replicators.

We must not overlook the adaptation that does and must occur in reality. After all, the move from a single person firm to an enterprise of three or four members involves considerable organizational development and adaptation, especially in complex and changing environments. A new division of labour would be required in the organization, with further moves towards the codification of some rules and tasks. Furthermore, given rapidly changing circumstances - new entrants, new technologies, new products, changing government policies - most firms are required to adapt to some degree, on an almost continuous basis, or face extinction.

The argument in the preceding paragraph finds a parallel in the evo-devo literature. Those that emphasize the development (devo) side of the story point out that selection does not operate directly on genes themselves. Selection operates on entities whose development was guided by genetic replicators in an environmental context. The objects of selection are interactors. Selection leads indirectly to changes in the population of hosted replicators. The two faces of selection are unavoidably connected by a developmental and adaptive process, which depends on both the replicators and how they express themselves in particular environments.

Although the detailed processes are very different, similar remarks apply to organizations and the replicators (habits and routines) that they host. Selection operates directly on organizations and individuals, which individually are outcomes of development in particular contexts.

While the relative importance of adaptation and selection can only be discovered by empirical enquiry, the generalized Darwinian framework shows that both processes are unavoidably present to some degree in biological and social evolution. The emergence of any biological organism and its ongoing adjustment to its environment involves massive, contextdependent change. Similarly the development of any firm from its small beginnings is an immense feat of adaptation. Hiring just one extra person in a small firm may involve a complete internal reconfiguration.

The evidence suggests that adaptation is slow and difficult (especially in larger firms) but that does not mean it can be ignored. Neglecting adaptation would overlook the difference between the information encoded in the replicator and its context-dependent expression in the developing interactor. Furthermore, simply to create a population of established firms upon which selection can operate requires the adaptive growth of every organization.

Furthermore, even if the possibilities for individual firm adaptation are limited, small differences in adaptive capacity from firm to firm may be crucial for survival. Consequently, even if much population-level change results largely from selection, the development of individual firms cannot be ignored in explanations of change or especially in the formulation of business strategies. 
As a result, some reconciliation may be possible between the organizational ecology approach, with its stress on selection and highly limited adaptation, and the business strategy literature, with its stress on the need for adaptability (Chaffee, 1985; McKee et al., 1989; Mintzberg and Quinn, 1991; Baum et al., 2006).

\section{Complexity and Organizational Evolution}

The adoption of the replicator-interactor distinction is not only important to clear up terminological confusion, it is also vital to understand the processes of organizational evolution. There are theoretical reasons why replicators are relevant in the social domain. Just as biological evolution has led eventually to organisms of greater sophistication and complexity, social and economic evolution is marked by an even more rapid increase in the complexity of technology and institutions in a relatively short period of human history.

In a few thousand years humans have evolved from primitive hunter-gatherers to inhabitants of complex civilizations. In a few hundred years we have seen the rise of capitalism and an explosion of scientific and technological knowledge. In a few decades we have observed a new phase of globalization and the evolution of complex business organizations and networks.

Is important to understand the necessary conditions under which complexity is enhanced in evolving population systems. The most basic and important general condition is the existence of replicators that can store and copy information to instruct and guide the development of their host entity (Hodgson and Knudsen, 2008, 2010a, 2010b). Another essential requirement is that copy error during replication is minimized. By contrast, both reading and developmental errors - which occur when using information from a source copy - do not corrupt the original information and are generally less serious. If the original information remains intact and is copied faithfully, then it might be retrieved. But if replication over time leads to the loss of information from the original, then it is gone forever. This argument suggests that replicators and faithful replication underlie the increasing complexity of social evolution. Some enduring fidelity in the copying of key information is a necessary condition for the evolution of complexity.

With social evolution the advance of complexity depends upon similar conditions. In a world of complexity and uncertainty, designed solutions to economic and business problems are difficult and risky. While some planning and guidance is desirable and unavoidable, we have to rely enormously on tried and tested knowledge.

Many successful firms do this (Stadler, 2007). Over one-third of all retail sales in the United States pass through chain organizations (Winter and Szulanski, 2001). Most successful chains expand by imposing a single organizational template on all chain outlets, including those that are franchised (Bradach, 1998). Similar replication strategies are found in firms when they develop new production plants in different locations. All these cases involve the strategic replication of habits and routines, replicating through a series of business units.

Consider Intel's 'Copy Exactly' factory strategy. This ramps up production quickly by copying everything at the development plant - the process flow, equipment set, suppliers, plumbing, manufacturing clean room, and training methodologies. Everything is selected to meet high volume needs, recorded, and then copied exactly.

Other prominent examples of firms that try to stimulate growth by reducing copy error include (Knudsen and Winter, unpublished): McDonalds, Burger King, Pizza Hut, Kentucky 
Fried Chicken; Holiday Inn, Novotel, Hilton (various brands). Marriott (various brands); Bank of America, Wachovia, HSBC; Merrill Lynch, Starbucks, Cosi; Office Depot, Staples; Borders, Barnes and Noble; Ikea, The Bombay Company; Benetton, Gap.

Business replication strategies that minimize copy error have become widespread through a combination of trial-and-error, and competitive selection weeding out firms with less successful policies. This theoretical argument may help to explain the otherwise puzzling observation that many firms grow by cloning existing arrangements as exactly as possible.

Given the existence of social replicators such as habits and routines, we need to understand the manner and degree in which these organizational replicators change. There might be fixed routines for adaptability, in which case an organization may be adaptable but have fixed 'genetic' recipes for adaptation. ${ }^{17}$ A pressing question for the business strategists is to what extent habits and routines can be changed, and if so how. Evidence suggests that they are generally difficult to change; executives that try top-down change with insufficient regard to underlying habits and routines are courting failure (Kolb, 2002; Stadler, 2007; Hodgson, 2011b). Because so much information held in habits and routines is tacit and inaccessible, business leaders cannot fully understand the knowledge stored in organizations (Nonaka and Takeuchi, 1995). This makes radical change from the top risky, and suggests that business strategies should be cautions and responsive to the opinions of workers in organizations.

Researching the 'genetics' of social evolution involves understanding the psychological and neurological mechanisms involved in these social processes, including a deep appreciation of how social structures and positions enable the retention of knowledge that relates to coordinated activity within organizations or teams.

\section{Replication, Routines, Inertia and Strategy}

This section points to further ways in which the framework of generalized Darwinism can guide research in organization studies. This is not primarily a process of applying biological analogies. Instead it is one of using an over-arching theoretical framework to guide and develop new lines of research.

Where vague terms such as 'evolution' and 'coevolution' typically obscure such distinctions, the difference between the diffusion of routines from organization to organization, on the one hand, and their inheritance through business spin-offs is crucial, as evidenced by empirical studies (Dahlstrand, 1998; Klepper, 2008; Bünstorf, 2009). This difference becomes clear through the replicator-interactor distinction, where routines are the replicators and organizations the interactors. Both processes involve replication. But diffusion involves existing interactor B copying a routine from interactor A. By contrast, spin-offs mean that interator $\mathrm{A}$ itself leads to the creation of a new interactor $\mathrm{B}$, which carries some routines from its parent. But empirical case studies suggest that the faithful copying of routines through diffusion is often more difficult than through spin-offs. Generalized Darwinism not only helps make clear distinctions but also points to important questions for empirical enquiry.

Far from conflating social with biological evolution, the conceptual framework of generalized Darwinism may be used to illuminate key differences between the two. As Nelson and Winter (1982) point out, firms can alter their own routines (replicators), whereas (outside modern genetic engineering) no biological organism can manipulate its genes (replicators). Furthermore, the diffusion of replicators (routines) from organization to organization is commonplace in the business world (Greenwood and Hinings, 1996). But diffusion is less 
prominent in biology, where generational replication through offspring is relatively more important. Clear concepts spanning different domains can illuminate detailed differences as well as abstract communalities.

The framework of generalized Darwinism is also useful in the context of debates concerning the roles of routine rigidity and strategic choice. It is a mistake to regard all 'evolutionary' approaches as rivals to other analyses that put the emphasis on the efficacy of strategic choice by managers (Child, 1972; Hrebeniak and Joyce, 1985). Far from dispensing with the role of individual agency, Darwinism inspired a huge cluster of multi-disciplinary studies on the evolution of brain, mind and behaviour (Richards, 1987), including the pragmatist approach mentioned above.

Crucially for this debate, the replicator concept in much of generalized Darwinism emphasizes that routines are dispositional and informational, rather than behaviour as such. By contrast, conceiving routines in terms of behaviour leads to mistaken notion that the definitional rigidity of the routine implies behavioural rigidity. The dispositional and informational conception (inspired by the refined replicator notion) makes it possible to combine routine rigidity with behavioural flexibility.

In writing this article I am making significant changes to an earlier draft, partly in response to useful comments by editors and referees. In an apparent paradox, I am using the rigid and unchanging software and hardware of my computer, along with inflexible rules of the English language, to produce one adaptive result out of an infinite number of possibilities. Rigid systems of rules, stored as information, can often be flexible in terms of behaviour. In some ways, organizational routines are like computer programs. They are complexes of rules, often triggered by sequential event and reliant on procedural memory (Cohen and Bacdayan, 1994). Their conditional nature and rule-like composition means that they can lead to branching trees of varied creative potentialities.

Furthermore, routines in an organization often link up with each other. Multiple levels exist, involving routines to monitor or change routines. Consider the strategic management technique known as scenario planning (Van der Heijden, 1996; Ringland, 1998; Chermack et al., 2001). This approach provides rules and guidelines to help generate multiple future scenarios facing organizations. In practice, the process may be routinized at various levels of management. A primary aim of scenario planning is to encourage managers on all levels to think outside the groove, to be flexible and to be more prepared for uncertain future changes. Flexibility requires some routinization. Scenario planning involves routines to encourage the innovation of routines and to make existing routines more adaptable.

Emerging and innovative organizations, led by dynamic entrepreneurs, cannot escape the need for routines. Entrepreneurs are not omniscient. Much valuable information in the firm has to be stored in the tacit knowledge of its employees. Consequently, as Brian Loasby (2007, p. 1104) explains, entrepreneurial and routine behaviours are complementary 'entrepreneurship defies routine; but it requires routine and results in routine'.

Both habits and routines can operate on multiple levels, often where some rule-like dispositions are above others in a developmental control hierarchy. ${ }^{18}$ But we should not jump to the description of 'multi-level evolution', as if that term were clear and unambiguous. The replicator-interactor framework poses the question whether multiple levels apply to interactors or replicators. Because hierarchical control systems among replicators (genes and organizational routines) are commonplace in complex population systems, the 'multi-level' term might best be reserved for hierarchically nested levels of interactors. ${ }^{19}$ Genuine multi- 
level evolution would occur where an organization has subsidiaries or other component interactors.

Emphatically, habits and routines do not imply the absence of choice (Dewey, 1922). In complex evolving systems there are bound to be conflicts between habits or routines. Habits may clash within an individual (the habit of reading, leading to an understanding of global warming, may lead to conflict with habitual car use), just as routines may conflict within an organization (a routinized audit may force a change of production or delivery methods). These conflicts create enhanced necessities for choice. When these clashes of routine are especially novel, there may not be routines in place to deal with the dilemma, and full strategic deliberation may be required. In any complex evolving social system, routinization generates rather than negates opportunities for strategic choice. In the absence of routine, organizational choice would be both overwhelming and ineffective.

Recent conceptions of the nature and role of strategy in business organizations as 'practical coping' (Chia and Holt, 2006) or as 'practical rationality' (Sandberg and Tsoukas, 2011) can dovetail with this overall framework. Organizational strategy is not a set of ideas or a set of practices relating to one individual. To be viable, it has to be largely embedded in habit and routine. Strategic development requires routinization. Strategic choice does not mean the abolition of automaticity.

The argument outlined in section five above shows that some copying fidelity of information held in organizational replicators is required for the evolution of complex outcomes in populations as well as the diffusion of that information itself. The combination of organizational structure and individual psychology militates against (but does not rule out_ change in individual organizations. Some evidence suggests that change becomes more difficult with the ageing of the organization (Bruderl and Schussler, 1990; Fichman and Levinthal, 1991; Barron et al., 1994). As organizations become more complex, it is more difficult for them to reconfigure their structures of interacting routines, and higher-level, agility-promoting routines become less effective. The principles of generalized Darwinism do not show that such outcomes are universal. Instead they provide a conceptual framework within which they can be understood. And they help to annul false dichotomies such as 'evolution' versus 'strategic choice'.

\section{Conclusions}

Organization science has been keen to address processes of change in organizations and organizational populations. Terms such as 'evolution' and 'coevolution' are commonplace but signify little. It is often unclear whether they refer to single entities or populations. With the development of the conceptual categories of generalized Darwinism, researchers into organizations are obliged to either adopt this framework or clarify the alternative type of evolutionary process involved. As yet, no adequate developed alternative framework exists for populations or organizations, where we are required to explain the processes of competitive selection, the sources of variation, and the manner of replication of key strategic information.

Adoption of the conceptual framework of generalized Darwinism has in part been blocked by misunderstandings and mischaracterizations. Previous objections turn out to be groundless. The adoption of Darwinian principles is not primarily a matter of analogy, but of ontological communality at an abstract level. 
The consideration of generalized Darwinism has further been thwarted by misleading terminology in the debate between selectionist and adaptationsit views on organizational change. There is no warrant to confine Darwinism to one side of this debate. Darwinism does not uphold that organizational development or adaptation are unimportant. Even if something like Lamarckian inheritance is apparent, Lamarckism is not an over-arching evolutionary framework. The framework of generalized Darwinism not only can accommodate differing empirical assessments of the relative importance of selection and adaptation, but also provide the conceptual structure for the development of detailed theories of organizational and industrial evolution (Stoelhorst and Huizing, 2006).

The version of generalized Darwinism promoted here makes use of the replicator-interactor distinction. Among the implications of this framework are the following:

First it underlines the need to identify social replicators (such as habits and routines) and interactors (organizations) and it emphasizes the crucial role of social replicators in retaining and helping to pass on knowledge.

Second, because replicators play a crucial role in the development of social interactors (organizations), and evolutionary selection acts directly upon organizations, the replicatorinteractor framework emphasizes the importance of both developmental adaptation and competitive selection in social evolution. It invalidates any dichotomy between these processes, and helps to reconcile insights from organization studies, organizational ecology and business strategy.

Third, the replicator-interactor framework is useful for helping to understand processes leading to greater complexity in social and business systems. A general theoretical argument underlines the importance of the copying fidelity of replicators in evolution. This also may help us to understand why so many successful business firms insist on exact copying of business routines when they establish or franchise new plants or outlets.

Fourth, the emphasis on the importance of social replicators and their capacity to store information underlines the likelihood that radical strategic change from the top of organizations carries high risks (Hodgson, 2011b). Because of its largely tacit nature, business executives can understand only a small part of the knowledge held in organizations. Leadership and entrepreneurship are important but may be over-emphasized. Successful business strategy must involve employees and address habits and routines at every level of the organization.

Fifth, the general conceptualization of the replicator within this framework implies an information-based conception of organizational routines. Addressing routines as rule-like, informational entities, rather than behaviours, overcomes the apparent conflict between routine rigidity and flexibility. Rigid conditional informational rules in routines can permit enormous behavioural flexibility. Furthermore, routines can interact with one another, and on different levels. There may be routines to modify routines. The dichotomy between routines and strategic choice evaporates.

Sixth, the replicator-interactor concepts permit much greater precision when addressing 'multi-level' evolution. The concepts promoted here immediately reveal the complications. There may be different levels of routines (replicators) in a single organization (interactor), Alternatively, evolutionary selection can operate on individuals, organizations, organizations of organizations, and so on. Multiple levels exist in both cases, but they are quite different. The framework of generalized Darwinism, including the complex concept of selection, provides a means of analysing both. 
Seventh, the application of Darwinian principles to the evolution of social entities opens up a further agenda by building a bridge with the rapidly-growing body of research on the evolution of social cooperation (Hammerstein, 2003; Henrich, 2004; Bowles and Gintis 2011). This research has clear implications for understanding cooperation within organizations (Hodgson 2013).

Although it has precedents going back to the late nineteenth century (Hodgson and Knudsen, 2010b, ch. 1), we are only at the beginning of this modern Darwinian research programme in the social sciences, and these are just a few of the possible insights and research questions that may emerge. The acceptance Darwinian principles combined with the discovery of the specific mechanisms involved in biology led to an explosion of productive research in biology that continues today. By using generalized Darwinian principles in the social domain, combined with a detailed understanding of the psychological and social mechanisms involved in the retention and replication of information in social organizations, we may be on the brink of a substantial expansion of our understanding of organizational evolution. Of course, further empirical research is vital. But clear concepts and theories are required to guide all enquiry and give it adequate meaning.

\section{Acknowledgements}

This essay draws on joint works with Thorbjørn Knudsen. Thanks are also due to Denise Dollimore, David Gindis, Anna Grandori, Stephen Herman, the editors of Organization Studies and anonymous referees for discussions and comments on earlier drafts.

\section{Funding}

This research received no specific grant from any funding agency in the public, commercial or not-for-profit sectors.

\section{References}

Adami, C., Ofria, C. and Collier, T. C. (2000) 'Evolution of Biological Complexity', Proceedings of the National Academy of Sciences, 97, 4463-4468.

Aldrich, H. E., Hodgson, G. M., Hull, D. L., Knudsen, T., Mokyr, J. and Vanberg, V. J. (2008) 'In Defence of Generalized Darwinism', Journal of Evolutionary Economics, 18, 577-596.

Ambros, V. (1989) 'A Hierarchy of Regulatory Genes Controls a Larva-to-Adult Developmental Switch in C. Elegans', Cell, 57, 49-57.

Baguñà, J. and Garcia-Fernàndez, J. (2003) 'Evo-Devo: The Long and Winding Road', International Journal of Developmental Biology, 47, 705-13.

Bannister, R. C. (1988) Social Darwinism; Science and Myth, second edition. Philadelphia: Temple University Press.

Barron, D. N., West, E. and Hannan, M. T. (1994) 'A Time of Growth and a Time to Die: Growth and Mortality of Credit Unions in New York, 1914-1990', American Journal of Sociology, 100, 381-421. 
Baum, J. A. C. (1996) 'Organizational Ecology', in Clegg, S. R., Hardy C. and Nord, W. R. (eds), Handbook of Organization Studies. London: Sage, 77-114.

Baum, J. A. C., Stanislav D. Dobrev, Arjen Van Witteloostuijn (eds) (2006) Ecology and Strategy (Advances in Strategic Management, Volume 23). Bingley: Emerald Group Publishing.

Becker, M. C. (ed.) (2008) Handbook of Organizational Routines. Cheltenham UK and Northampton MA: Edward Elgar.

Beinhocker, E. D. (2006) The Origins of Wealth: Evolution, Complexity, and the Radical Remaking of Economics. New York: Random House.

Beinhocker, E. D. (2011) 'Evolution as Computation: Integrating Self-Organization with Generalized Darwinism', Journal of Institutional Economics, 7, 393-423.

Boesiger, E. (1974) 'Evolutionary Theories after Lamarck and Darwin' in Ayala, F. J. and Dobzhansky, T. (eds) (1974) Studies in the Philosophy of Biology. London, Berkeley and Los Angeles: Macmillan and University of California Press, pp. 21-44.

Bowles, S. and Gintis, H. (2011) A Cooperative Species: Human Reciprocity and its Evolution. Princeton, NJ: Princeton University Press.

Boyd, R. and Richerson, P. J. (1985) Culture and the Evolutionary Process. Chicago: University of Chicago Press.

Bradach, J. L. (1998) Franchise Organizations. Boston, MA: Harvard Business School Press.

Brandon, R. N. (1996) Concepts and Methods in Evolutionary Biology, Cambridge and New York: Cambridge University Press.

Brennan, R. and Turnbull, P. (1999) 'Adaptive Behaviour in Buyer-Seller Relationships', Industrial Marketing Management, 28, 481-495.

Bruderl, J. and Schussler, R. (1990) 'Organizational Mortality: The Liabilities of Newness and Adolescence', Administrative Science Quarterly, 35, 530-547.

Bünstorf, G. (2009) 'Opportunity Spin-Offs and Necessity Spin-Offs', International Journal of Entrepreneurial Venturing, 1, 22-40.

Burkhardt, R. W., Jr (1977) The Spirit of System: Lamarck and Evolutionary Biology. Cambridge, MA: Harvard University Press.

Camic, C. and Hodgson, G. M. (eds) (2011) Essential Writings of Thorstein Veblen. London and New York: Routledge.

Campbell, D. T. (1965) 'Variation, Selection and Retention in Sociocultural Evolution', in Barringer, H. R., Blanksten, G. I. and Mack, R. W. (eds) (1965) Social Change in Developing Areas: A Reinterpretation of Evolutionary Theory. Cambridge, MA: Schenkman, pp. 19-49.

Chaffee, E.-E. (1985) 'Three Models of Strategy', Academy of Management Review, 10, 8998.

Chermack, T. J., Lynham, S. A. and Ruona, W. E. A. (2001) 'A Review of Scenario Planning Literature', Futures Research Quarterly, 7, 7-32.

Chia, R. and Holt, R. (2006) 'Strategy as Practical Coping: A Heideggerian Perspective', Organization Studies, 27, 635-655. 
Child, J. (1972) 'Organisational Structure, Environment and Performance: The Role of Strategic Choice', Sociology, 6, 1-22.

Cohen, M. D. and Bacdayan, P. (1994) 'Organizational Routines are Stored as Procedural Memory - Evidence from a Laboratory Study’, Organization Science, 5, 554-568.

Cohen, M. D., Burkhart, R., Dosi, G., Egidi, M., Marengo, L., Warglien, M., and Winter, S. G. (1996) 'Routines and Other Recurring Action Patterns of Organizations: Contemporary Research Issues', Industrial and Corporate Change, 5, 653-698.

Cordes, C. (2006) 'Darwinism in Economics: From Analogy to Continuity', Journal of Evolutionary Economics, 16(5), December, pp. 529-41.

Dahlstrand, Å. L. (1998) 'Growth and Inventiveness in Technology-Based Spin-Off Firms', Research Policy, 26, 331-344.

Darwin, C. R. (1859) On the Origin of Species by Means of Natural Selection, or the Preservation of Favoured Races in the Struggle for Life. London: Murray.

Darwin, C. R. (1868) The Variation of Animals and Plants Under Domestication, 2 vols. London and New York: Murray and Orange Judd.

Darwin, C. R. (1974) Metaphysics, Materialism, and the Evolution of Mind: Early Writings of Charles Darwin, transcribed and annotated by Paul H. Barrett with a commentary by Howard E. Gruber. Chicago: University of Chicago Press.

Dawkins, R. (1986) The Blind Watchmaker. Harlow: Longman.

Degler, C. N. (1991) In Search of Human Nature: The Decline and Revival of Darwinism in American Social Thought. Oxford and New York: Oxford University Press.

Dewey, J. (1922) Human Nature and Conduct: An Introduction to Social Psychology. New York: Holt.

Fichman, M. and Levinthal, D. A. (1991) 'Honeymoons and the Liability of Adolescence: A New Perspective on Duration Dependence in Social and Organizational Relationships', Academy of Management Review, 16, 442-468.

Jablonka, E. and Lamb, M. J. (2002) 'The Changing Concept of Epigenetics', Annals of the New York Academy of Sciences, 981, 82-96.

Gould, S. J. (1980) The Panda's Thumb: More Reflections in Natural History. New York: Norton.

Greenwood, R. and Hinings, C. R. (1996) 'Understanding Radical Organizational Change: Bringing Together the Old and the New Institutionalism', Academy of Management Review, 21, 1022-1054.

Hammerstein, P. (ed.) (2003) Genetic and Cultural Evolution of Cooperation. Cambridge, MA: MIT Press.

Hannan, M. T. and Freeman, J. (1989) Organizational Ecology. Cambridge, MA: Harvard University Press.

Hayek, F. A. (1988) The Fatal Conceit: The Errors of Socialism. The Collected Works of Friedrich August Hayek, Vol. I, ed. W. W. Bartley III. London: Routledge.

Henrich, J. (2004) 'Cultural Group Selection, Coevolutionary Processes and Large-Scale Cooperation', Journal of Economic Behavior and Organization, 53, 3-35. 
Hodgson, G. M. (1993) Economics and Evolution: Bringing Life Back Into Economics. Cambridge, UK and Ann Arbor, MI: Polity Press and University of Michigan Press.

Hodgson, G. M. (2002) 'Darwinism in Economics: From Analogy to Ontology', Journal of Evolutionary Economics, 12, 259-281.

Hodgson, G. M. (2004) 'Social Darwinism in Anglophone Academic Journals: A Contribution to the History of the Term', Journal of Historical Sociology, 17, 428-463.

Hodgson, G. M. (2006) Economics in the Shadows of Darwin and Marx: Essays on Institutional and Evolutionary Themes. Cheltenham: Edward Elgar.

Hodgson, G. M. (2007) 'A Response to Christian Cordes and Clifford Poirot', Journal of Economic Issues, 41, 265-276.

Hodgson, G. M. (2008). 'The Concept of a Routine', in Markus C. Becker (ed.) (2008) Handbook of Organizational Routines. Cheltenham UK and Northampton MA: Edward Elgar, 3-14.

Hodgson, G. M. (2010) 'Choice, Habit and Evolution', Journal of Evolutionary Economics, 20,1-18.

Hodgson, G. M. (2011a) 'Organizational Evolution versus the Cult of Change', Corporate Finance Review, 16, 5-10.

Hodgson, G. M. (2011b) 'A Philosophical Perspective on Contemporary Evolutionary Economics' in J. B. Davis and D. W. Hands (eds) The Elgar Companion to Recent Developments in Economic Methodology. Cheltenham UK and Northampton MA: Edward Elgar, 299-318.

Hodgson, G. M. (2013) From Pleasure Machines to Moral Communities: An Evolutionary Economics without Homo Economicus. Chicago: University of Chicago Press.

Hodgson, G. M. and Knudsen, T. (2006a) 'Why We Need a Generalized Darwinism: and Why a Generalized Darwinism is Not Enough', Journal of Economic Behavior and Organization, 61, 1-19.

Hodgson, G. M. and Knudsen, T. (2006b) 'Dismantling Lamarckism: Why Descriptions of Socio-Economic Evolution as Lamarckian are Misleading', Journal of Evolutionary Economics, 16, 343-66.

Hodgson, G. M. and Knudsen, T. (2008) 'Information, Complexity and Generative Replication', Biology and Philosophy, 43, 47-65.

Hodgson, G. M. and Knudsen, T. (2010a) 'Generative Replication and the Evolution of Complexity', Journal of Economic Behavior and Organization, 75, 12-24.

Hodgson, G. M. and Knudsen, T. (2010b) Darwin's Conjecture: The Search for General Principles of Social and Economic Evolution. Chicago: University of Chicago Press.

Hrebeniak, L. G. and Joyce, W. F. (1985) 'Organisational Adaptation: Strategic Choice and Environmental Determinism', Administrative Science Quarterly, 30, 336-349.

Hull, D. L. (1982) 'The Naked Meme', in Plotkin, H. C. (ed.) (1982) Learning, Development and Culture: Essays in Evolutionary Epistemology. New York: Wiley, 273-327.

Hull, D. L. (1988) Science as a Process: An Evolutionary Account of the Social and Conceptual Development of Science. Chicago: University of Chicago Press. 
Huygens, M., Baden-Fuller, C., Van Den Bosch, F. A. J. and Volberda, H. W. (2001) 'CoEvolution of Firm Capabilities and Industry Competition: Investigating the Music Industry 1877-1997', Organization Studies, 22, 971-1011

James, W. (1890) The Principles of Psychology, 2 vols. New York and London: Holt and Macmillan.

Jenkins, M. and Floyd, S. W. (2001) 'Trajectories in the Evolution of Technology: A Multi-level Study of Competition in Formula 1 Racing', Organization Studies, 22, 945-969.

Joas, H. (1993) Pragmatism and Social Theory. Chicago: University of Chicago Press.

Jones, C. (2001) 'Co-Evolution of Entrepreneurial Careers, Institutional Rules and Comprehensive Dynamics in American Film, 1895-1920', Organization Studies, 22, 911944.

Klepper, S. (2008) 'Silicon Valley - A Chip off the Old Detroit Bloc', in D. B. Audretsch and R. Strom (eds) (2008) Entrepreneurship, Growth, and Public Policy. Cambridge UK: Cambridge University Press, pp. 79-118.

Knudsen, T. and Winter, S. G. (unpublished) 'An Evolutionary Model of Spatial Competition'.

Kolb, D. G. (2002) 'Continuity, Not Change: The Next Organisational Challenge', University of Auckland Business Review, 4, 1-11.

Lamarck, J. B. de (1984) Zoological Philosophy: An Exposition with Regard to the Natural History of Animals, translated by H. Elliot from the 1st French edn. of 1809 with introductory essays by D. L. Hull and R. W. Burkhardt. Chicago: University of Chicago Press.

Levinthal, D. A. (1992) 'Surviving Schumpeterian Environments: An Evolutionary Perspective', Industrial and Corporate Change, 1, 427-443.

Lewin, A. Y. and Koza, M. P. (2001) 'Editorial', Organization Studies, 22, v-xii.

Lewin, A. Y. and Volberda, H. W. (1999) 'Prolegmean on Coevolution: A Framework for Research on Strategy and New Organizational Forms', Organization Science, 10, 519-534.

Lewin, A. Y. and Volberda, H. W. (2003) 'The Future of Organization Studies: Beyond the Selection-Adaptation Debate', in Tsoukas, H. and Knudsen, C. (eds) (2003) The Oxford Handbook of Organization Theory: Meta-Theoretical Perspectives. Oxford and New York: Oxford University Press, 568-595.

Loasby, B. J. (2007) 'A Cognitive Perspective on Entrepreneurship and the Firm', Journal of Management Studies, 44, 1078-1106.

McKee, D. O., Varadarajan, P. R. and Pride, W. M. (1989) 'Strategic Adapatability and Firm Performance: A Market-Contingent Perspective', Journal of Marketing, 53, 21-35.

McKelvey, W. (1982) Organizational Systematics: Taxonomy, Evolution, Classification. Berkeley, CA: University of California Press.

Metcalfe, J. S. (1998) Evolutionary Economics and Creative Destruction. London and New York: Routledge.

Mintzberg, H. and Quinn, J. B. (1991) The Strategy Process: Concepts, Contexts, Cases. Englewood Cliffs, NJ: Prentice-Hall. 
Nelson, R. R. (1991) 'Why Do Firms Differ, and How Does it Matter?', Strategic Management Journal, 12, Special Issue, 61-74.

Nelson, R. R. (2006) 'Evolutionary Social Science and Universal Darwinism', Journal of Evolutionary Economics, 16, 491-510.

Nelson, R. R. and Winter, S. G. (1982) An Evolutionary Theory of Economic Change. Cambridge, MA: Harvard University Press.

Nonaka, I. and Takeuchi, H. (1995) The Knowledge-Creating Company: How Japanese Companies Create the Dynamics of Innovation. Oxford and New York: Oxford University Press.

Peirce, C. S. (1878) 'How to Make Our Ideas Clear', Popular Science Monthly, 12, 286-302.

Pelikan, P. (2011) 'Evolutionary Developmental Economics: How to Generalize Darwinism Fruitfully to help Comprehend Economic Change', Journal of Evolutionary Economics, 21, 341-366.

Pennisi, E. (2008) 'Modernizing the Modern Synthesis', Science, 321, no. 5886, 196-197.

Price, G. R. (1995) 'The Nature of Selection', Journal of Theoretical Biology, 175, 389-396.

Reydon, T. A. and Scholz, M. (2009) 'Why Organizational Ecology Is Not a Darwinian Research Programme', Philosophy of the Social Sciences, 39, 408-439..

Richards, R. J. (1987) Darwin and the Emergence of Evolutionary Theories of Mind and Behavior. Chicago: University of Chicago Press.

Ringland, G. (1998) Scenario Planning: Managing for the Future. Chichester: Wiley.

Rodrigues, S. B. and Child, J. (2003) 'Co-evolution and transformation in times of deconstruction: A dynamic multi-level process'. Journal of Management Studies, 40, $2137-2162$.

Sandberg, J. and Haridimos, T. (2011) 'Grasping the Logic of Practice: Theorizing Through Practical Rationality’, Academy of Management Review, 36, 338-360.

Schein, E. H. (1996) 'Culture: The Missing Concept in Organization Studies', Administrative Science Quarterly, 41, 229-240.

Shannon, C. E., and Weaver, W. (1949) The Mathematical Theory of Communication. Chicago: University of Illinois Press.

Sober, E. and Wilson, D. S. (1998) Unto Others: The Evolution and Psychology of Unselfish Behavior (Cambridge, MA: Harvard University Press).

Sørensen, J. B. (2002) 'The Strength of Corporate Culture and the Reliability of Firm Performance', Administrative Science Quarterly, 47, 70-91.

Stadler, B. M. R., Stadler, P. F., and Wagner, G. P. (2001) 'The Topology of the Possible: Formal Spaces Underlying Patterns of Evolutionary Change', Journal of Theoretical Biology, 213, 241-274.

Stadler, C. (2007) 'The Four Principles of Enduring Business Success', Harvard Business Review, July-August, 62-72.

Stoelhorst, J.-W. (2005) 'The Naturalist View of Universal Darwinism: An Application to the Evolutionary Theory of the Firm', in Finch, J. and Orillard, M. (2005) Complexity and the 
Economy: Implications for Economic Policy. Cheltenham, UK and Northamption, MA: Edward Elgar, pp. 127-147.

Stoelhorst, J.-W. (2008) 'The Explanatory Logic and Ontological Commitments of Generalized Darwinism', Journal of Economic Methodology, 15, 343-363.

Stoelhorst, J.-W. and Huizing, A. (2006) 'Why the Adaptation-Selection Debate is Misconstrued: A Darwinian view of Organizational Change', Sprouts: Working Papers on Information Systems, 6(16). http://sprouts.aisnet.org/6-16. Retrieved 14 March 2011.

Usher, J. M. and Evans, M. G. (1996) 'Life and Death along Gasoline Alley: Darwinian and Lamarckian Processes in a Differentiating Population', Academy of Management Journal, 39, 1428-1466.

Van de Ven, A. H. and Poole, M. S. (1995) 'Explaining Development and Change in Organizations', Academy of Management Review, 20, 510-540.

Van der Heijden, K. A. J. M. (1996) Scenarios: The Art of Strategic Conversation. Chichester: Wiley.

Veblen, T. B. (1899) The Theory of the Leisure Class: An Economic Study in the Evolution of Institutions. New York: Macmillan.

Wilkins, J. S. (2001) 'The Appearance of Lamarckism in the Evolution of Culture', in Laurent, J. and Nightingale, J. (eds) (2001) Darwinism and Evolutionary Economics. Cheltenham: Edward Elgar, pp. 160-183.

Wimsatt, W. C. (1999) 'Genes, Memes, and Cultural Heredity', Biology and Philosophy, 14, 279-310.

Winter, S. G. and Szulanski, G. (2001) 'Replication as Strategy', Organization Science, 12, 730-743.

Witt, U. (2008) 'What is Specific about Evolutionary Economics?', Journal of Evolutionary Economics, 18 , pp. 547-575

\section{Author biography}

Geoffrey M. Hodgson is a Research Professor at Hertfordshire Business School at the University of Hertfordshire in England. His books include From Pleasure Machines to Moral Communities (2013), Darwin's Conjecture (2010, with Thorbjørn Knudsen), The Evolution of Institutional Economics (2004) and How Economics Forgot History (2001). Having published widely in the academic journals, he is an Academician of the UK Academy of Social Sciences and he serves as Editor-in-Chief of the Journal of Institutional Economics. His website is www.geoffrey-hodgson.info.

\section{Notes}

${ }^{1}$ Actually the conceptual; triplet comes in different forms, with others using the terms 'variation, selection and replication' or 'variation, selection and inheritance'.

${ }^{2}$ Lewin and Volberda (1999, p. 523) and Lewin and Koza (2001, p. v) include Max Weber and Alfred Chandler as exponents of 'evolutionary theory', and they do so in the 2001 article 
in the very same paragraph that they briefly mention 'variation, selection, and retention'. In fact, neither Weber nor Chandler made much of this conceptual triplet. We are not informed that the 'variation, selection, and retention' formulation is particularly associated with a classic essay by Donald T. Campbell (1965) which explicitly describes these concepts as Darwinian and pioneered their application to social evolution.

3 Much of the rhetoric on 'social Darwinism' attacks a largely mythological and inappropriately described invention of the critics (Bannister, 1988; Hodgson, 2004, 2006). See Hodgson and Knudsen (2010b) for criticism of other misguided rejections of Darwinism. Critiques of generalized Darwinism by Cordes (2006), Witt (2008) and others are also answered elsewhere (Hodgson, 2007, 2011a). Nelson (2006) broadly supports generalized Darwinism, except for misgivings about the replicator-interactor framework.

${ }^{4}$ Examples include classic texts by McKelvey (1982), Nelson and Winter (1982), Boyd and Richerson (1985), and Hayek (1988).

${ }^{5}$ To add further confusion, Reydon and Scholz (2009) have recently argued that the work of Hannan and Freeman (1989) and McKelvey (1982) is not 'Darwinian' because it lacks an adequate explanation of organizational diversity. But if true, this would not mean that this work was un-Darwinian, but simply that their Darwinian account was incomplete. Incomplete Darwinism does not disqualify the Darwinian label: it means that more work must be done within the Darwinian framework. For the Darwinian label to be unwarranted the approach would have to be incompatible with Darwinism. This is not the case.

${ }^{6}$ In fact, Jean Baptiste de Lamarck ([1809] 1984) promoted the first and second of these only (Boesiger, 1974; Burkhardt, 1977).

${ }^{7}$ There is evidence of epigenetic inheritance (Pennisi, 2008). If the environment affects gene expression rather than genes themselves it is debatable whether it is Lamarckian. If it goes further to affect the DNA, then the case is stronger. But this issue within biology does not affect the argument here, and leading investigators of epigenetics concur that Darwinism and Lamarckism are theoretically compatible (Jablonka and Lamb, 2002).

${ }^{8}$ Darwin knew nothing of genes but anticipated the general idea of inherited information in organisms. Throughout Origin and other writings, Darwin describes how inherited modifications are preserved in 'instincts' and 'germ cells.' 'Germ' is mentioned in Darwin's Notebook B and E and instincts are mentioned in almost all his notebooks (Darwin, 1974). In his theory of 'pangenesis', Darwin (1868) conjectured (wrongly) that information is preserved and inherited via 'gemmules' given off by cells in the bloodstream.

${ }^{9}$ The versions of generalized Darwinism in Hull (1988) and Hodgson and Knudsen (2006b, 2010b) emphasize the replicator and interactor concepts. These are prefigured in Darwin's work (see preceding footnote) and are essential to distinguish phenomena such as contagion from inheritance.

${ }^{10}$ Information here means a code or signal, as stored and manipulated by computers and present in DNA. A message has 'information content' when its receipt causes some action (Shannon and Weaver, 1949). With social evolution it is essential to bring meanings and interpretations into the picture. Not all theorists define replicators in this way. The 
informational and rule-based definition is defended in Hodgson and Knudsen (2010b). It concurs with the view that Darwinian evolution is very much about the selection, retention and development of more complex information (Adami et al., 2001; Beinhocker, 2006, 2011).

${ }^{11}$ There is some confusion in Nelson and Winter (1982) because routines carry inheritable instructions (like genotypes or replicators) and are also regarded by them as the expression of these instructions (like phenotypes or interactors) (Hodgson, 2008).

12 The pragmatist approach is strikingly similar in key respects to notions of business strategy as 'practical coping' (Chia and Holt, 2006) or 'practical rationality' (Sandberg and Haridimos, 2011).

${ }^{13}$ The copying of habits of thought is more complex and it relies on language (Hodgson and Knudsen, 2010b, pp. 138-9).

${ }^{14}$ Although there is a 'Lamarckian' link from our behaviour to our habit, it is a causal cul-desac. It plays no part in the inheritance process. This is very different from any imagined Lamarckian process in biology. In the biological sphere, replicators get copied directly. Similar arguments apply to the replication of organizational routines, because that process too is grounded on the replication of individual habits (Hodgson and Knudsen, 2006a, 2006b, 2010b).

${ }^{15}$ See Hodgson and Knudsen (2010b) for critical discussions of other purportedly rival approaches such as 'self-organization theory'.

${ }^{16}$ But it does not imply that selection as a process always leads to improvement or efficiency. As in biology, selection can lead to sub-optimal outcomes (Gould, 1980; Hodgson, 1993, ch. 13). Selection itself is not a straightforward concept. It can come in different forms, notably subset selection and successor selection (Price, 1995; Hodgson and Knudsen, 2010b). Many 'selectionist' accounts focus on subset selection only. Successor selection involves generational transmission: this occurs with business spin-offs.

${ }^{17}$ Emphatically the terms 'genetic' or 'genetics' in inverted commas do not refer to actual genes but social replicators (such as habits or routines) that store information in social processes. The usage is metaphorical rather than literal, and it is intended to point to ontological communality at a more abstract level only.

${ }^{18}$ Incidentally, similar remarks apply to biological genes (Ambros, 1989).

${ }^{19}$ A prominent example is group selection (Sober and Wilson, 1998; Henrich, 2004). Here both groups and individuals are interactors and objects of selection. The outcomes of selection can be observed in the population at the level of cultural or genetic replicators. The 'group selection' term refers to the higher level interactor, not to any replicator. 